\title{
INTRAOPERATIVE HEMODYNAMIC ASSESSMENT OF GASTROEPIPLOIC ARTERY AND SAPHENOUS VEN BYPASS GRAFTS: A COMPARATIVE STUDY
}

Yves A. G. Louagie, MD, PhD

Jacques Jamart, MD

Michel Buche, MD

Philippe Eucher, MD

Paul van San, Eng

Serge Theys, MSc

Jean-Claude Schoevaerdts, MD
Objective: Blood flow characteristics of right gastroepiploic artery and saphenous vein conduits were compared during bypass surgery. Methods: This study is based on a consecutive series of 97 patients undergoing a bypass graft to the right coronary artery, posterior descending artery, or posterolateral branch using either a pediculated right gastroepiploic artery $(n=52)$ or a saphenous vein $(n=45)$ bypass graft. Flows and velocity profiles were measured with an 8-MHz pulsed-wave Doppler ultrasound flowmeter. Thorough flow measurements were made (1) after cessation of cardiopulmonary bypass and (2) before chest closure. Results: At the end of cardiopulmonary bypass, flow in the right gastroepiploic artery $(59.0 \pm 6.7 \mathrm{~mL} / \mathrm{min})$ did not differ $(P=.08)$ from flow in the saphenous vein $(46.1 \pm 2.7 \mathrm{~mL} / \mathrm{min})$. Mean trace velocity was $11.9 \pm 0.7 \mathrm{~cm} / \mathrm{s}$ in the right gastroepiploic artery and $11.6 \pm 0.8 \mathrm{~cm} / \mathrm{s}$ in the saphenous vein $(P=.80)$, but peak systolic velocity was $29.4 \pm 1.2$ $\mathrm{cm} / \mathrm{s}$ for the right gastroepiploic artery and $23.1 \pm 1.3 \mathrm{~cm} / \mathrm{s}$ for the saphenous vein $(P<.001)$. Likewise, before chest closure, flow was 57.1 $\pm 4.7 \mathrm{~mL} / \mathrm{min}$ in the right gastroepiploic artery and $46.5 \pm 4.0 \mathrm{~mL} / \mathrm{min}$ in the saphenous vein $(P=.10)$, mean velocity was $12.9 \pm 0.7$ and $11.6 \pm$ $0.8 \mathrm{~cm} / \mathrm{s}$, respectively $(P=.22)$, and systolic peak velocity was $30.0 \pm 1.2$ and $22.3 \pm 1.2 \mathrm{~cm} / \mathrm{s}$, respectively $(P<.001)$. Conclusions: There were no flow differences between right gastroepiploic artery and saphenous vein grafts implanted into the same coronary bed in comparable groups of patients. Waveform shape of the right gastroepiploic artery grafts was characterized by a wider spectral dispersion resulting in a higher maximal frequency. (J Thorac Cardiovasc Surg 1999;118:330-8)
$\mathrm{D}$ espite a late patency rate better than $80 \%,{ }^{1,2}$ the right gastroepiploic artery (RGEA) is considered as an alternative arterial conduit and remains underused. Indeed, the RGEA is a highly vasoreactive artery as demonstrated by in vitro pharmacologic studies ${ }^{3-6}$ and in the clinical setting. ${ }^{7-11}$ Cases of poor graft performance leading rapidly to postoperative ischemia have been published. ${ }^{12}$ In addition, these grafts are characterized by their extreme vulnerability to twisting, kinking, and

From the Divisions of Cardiovascular and Thoracic Surgery, Biostatistics, and Vascular Laboratory of the University Clinics of Mont Godinne, Université Catholique de Louvain, Mont-Yvoir, Belgium.

Received for publication Oct 13, 1998; revisions requested Nov 20, 1998; revisions received April 12, 1999; accepted for publication April 13, 1999.

Address for reprints: Yves Louagie, MD, Cardiovascular and Thoracic Surgery, University Hospital of Mont Godinne, 1 av Therasse, B-5530 Mont-Yvoir, Belgium.

Copyright (C) 1999 by Mosby, Inc.

$0022-5223 / 99 \$ 8.00+0 \quad \mathbf{1 2 / 1 / 9 9 2 2 8}$ technical error of the skeletonized RGEA in the area of the anastomosis. This is confirmed by the significant learning curve necessary to achieve satisfactory patency results. ${ }^{13}$ Finally, it was suggested that arterial grafts originating from a systolic-dominant circulation far away from the heart may have a limited ability to supply blood to the diastolic-dominant coronary circulation. ${ }^{14}$ Surprisingly, though the intraoperative flow potential of the RGEA may be limited, only a few studies specifically addressing the problem are available. ${ }^{12,15}$

The aim of the present investigation was to assess immediate flow adequacy of RGEA grafts and to demonstrate a potential for intraoperative spasticity of the artery. Flow measurements were done (1) immediately on cessation of cardiopulmonary bypass (CPB) and (2) before chest closure. Continuous velocity in the RGEA grafts was monitored and was compared with that of greater saphenous vein (GSV) conduits to identify a reversible flow reduction related to spasm of the RGEA. The hypothesis tested was that the flow and 
Table I. Preoperative demographic characteristics

\begin{tabular}{lccc}
\hline & RGEA & GSV & P value \\
\hline Number & 52 & 45 & \\
Age (y) & $60.4 \pm 1.3$ & $70.8 \pm 0.9$ & .001 \\
Sex (M/F) & $38 / 14$ & $26 / 19$ & .28 \\
FC angina & & & \\
$\quad$ Class I & $3(5.8)$ & $2(4.4)$ & \\
Class II & $21(40.4)$ & $7(15.6)$ & .01 \\
Class III & $14(26.9)$ & $15(33.3)$ & \\
Class IV & $14(26.9)$ & $21(46.7)$ & \\
Old (>6 wk) MI & $18(34.6)$ & $20(44.4)$ & .39 \\
Recent (<6 wk) MI & $4(7.7)$ & $3(6.7)$ & .87 \\
Smoking habits & $25(48.1)$ & $18(40.0)$ & .68 \\
Obesity & $19(36.5)$ & $15(33.3)$ & .43 \\
Renal insufficiency & $0(0.0)$ & $2(4.4)$ & .29 \\
Hypertension & $17(32.7)$ & $22(48.9)$ & .18 \\
Dyslipidemia & $23(44.2)$ & $14(31.1)$ & .41 \\
Diabetes mellitus & $17(32.7)$ & $16(35.6)$ & .45 \\
Lung obstructive disease & $1(1.9)$ & $7(15.6)$ & .04 \\
Lower limb arteritis & $6(11.5)$ & $7(15.6)$ & .67 \\
Previous CABG & $7(13.5)$ & $1(2.2)$ & .05 \\
\hline
\end{tabular}

Numbers between parentheses are percent values. RGEA, Right gastroepiploic artery; $G S V$, greater saphenous vein; $M / F$, male/female; $F C$, functional class; $M I$, myocardial infarction; $C A B G$, coronary artery bypass grafting.

velocity patterns would differ significantly between the 2 conduits.

\section{Methods}

Patient characteristics. Ninety-seven consecutive patients undergoing bypass grafting onto a recipient artery that can be reached by a pediculated RGEA (right coronary artery, posterior descending artery, or a posterolateral branch) form the basis of this study. Only 1 patient underwent an associated cardiac procedure (mitral valve replacement).

Our usual indications for selecting one of the conduits were as follows: In brief, an RGEA was chosen in young patients or in the absence of an adequate saphenous vein. Contraindications to RGEA grafting consisted of antecedents of gastrectomy or cholecystectomy, stenosis of the celiac trunk as evidenced at preoperative angiography, chronic obstructive lung disease, and hepatomegaly. By contrast, the characteristics of the recipient coronary artery and of the related myocardial segment were not taken into account. The demographics of the patients are summarized in Table I. The patients receiving a GSV were older, had more severe angina, and had a higher incidence of obstructive lung disease. Results of preoperative angiography are compared in Table II. There were no significant differences in the extent of coronary disease, dominance, and degree of stenosis of the recipient artery, except for a higher incidence of left main stem disease in the GSV group. Finally, preoperative contrast ventriculography and echocardiography were similar regarding the function of the myocardial segments supplied by the right coronary system. Ejection fraction as determined by
Table II. Results of coronary angiography

\begin{tabular}{lccr}
\hline & $\begin{array}{c}R G E A \\
(n=52)\end{array}$ & $\begin{array}{c}G S V \\
(n=45)\end{array}$ & P value \\
\hline Extent of coronary disease & & & \\
One vessel & $1(1.9)$ & $0(0.0)$ & 1.00 \\
Two vessels & $15(28.8)$ & $11(24.4)$ & .65 \\
Three vessels & $36(69.2)$ & $34(75.6)$ & .51 \\
Left main stem disease & $2(3.8)$ & $9(20.0)$ & .03 \\
Categories of stenoses & & & \\
51\%-70\% & & & .41 \\
RCA & $2(3.8)$ & $4(8.9)$ & 1.00 \\
PDA & $2(3.8)$ & $1(2.2)$ & 1.00 \\
PL & $1(1.9)$ & $0(0.0)$ & .19 \\
$71 \%-90 \%$ & & & .34 \\
RCA & $13(25.0)$ & $17(37.8)$ & .47 \\
PDA & $4(7.7)$ & $7(15.6)$ & \\
PL & $3(5.8)$ & $5(11.1)$ & .06 \\
$91 \%-99 \%$ & & & .60 \\
RCA & $5(9.6)$ & $0(0.0)$ & \\
PDA & $1(1.9)$ & $2(4.4)$ & .68 \\
PL & $0(0.0)$ & $0(0.0)$ & -21 \\
100\% & & & 1.00 \\
RCA & $24(46.2)$ & $18(40.0)$ \\
PDA & $8(15.4)$ & $3(6.7)$ & $1(2.2)$ \\
PL & $1(1.9)$ & & \\
\hline
\end{tabular}

$\overline{\text { Numbers between parentheses are percent values. } R G E A \text {, Right gastroepiploic }}$ artery; $R C A$, right coronary artery; $P D A$, posterior descending artery; $P L$, posterolateral branch.

angiography was $61 \% \pm 2 \%$ in the RGEA group and $57 \% \pm$ $4 \%$ in the GSV group $(P=.67)$.

Surgical technique. All the procedures were performed by one surgeon (Y.L.) using identical techniques. The RGEA was dissected from the greater gastric curvature with the aid of Hemoclip ligating clips (Weck Closure Systems, Research Triangle Park, NC), brought anterior to the stomach and liver and directed through a diaphragmatic hole toward the inferior aspect of the heart. Before the start of $\mathrm{CPB}, 2 \mathrm{~mL}$ of undiluted papaverine hydrochloride was injected at $37^{\circ} \mathrm{C}$ into the distal end of the RGEA without mechanical dilation with an olive-tipped (1 mm) metal needle (DLP, Inc, Grand Rapids, Mich, No. 31001). To obtain an adequate diameter, we discarded excess length. The aorta was crossclamped, the heart was arrested with cold blood cardioplegic solution administered retrogradely, and core temperature was reduced to $28^{\circ} \mathrm{C}$. All coronary anastomoses were performed first during a single aortic crossclamp period with the aid of $6 \times$ optical magnification, using 8-0 polypropylene running suture. Only coronary arteries having an internal diameter greater than 1.0 $\mathrm{mm}$ were grafted. The quality of the coronary arteries grafted did not differ between the groups. Specifically, the proportion of diffusely atheromatous or heavily calcified coronary arteries and anastomotic plaques was similar in the 2 groups.

Flow measurements. Flows were measured with an 8$\mathrm{MHz}$ pulsed-wave Doppler ultrasound flowmeter (OPDOP 130; Scimed, Bristol, United Kingdom). For the GSV, record- 


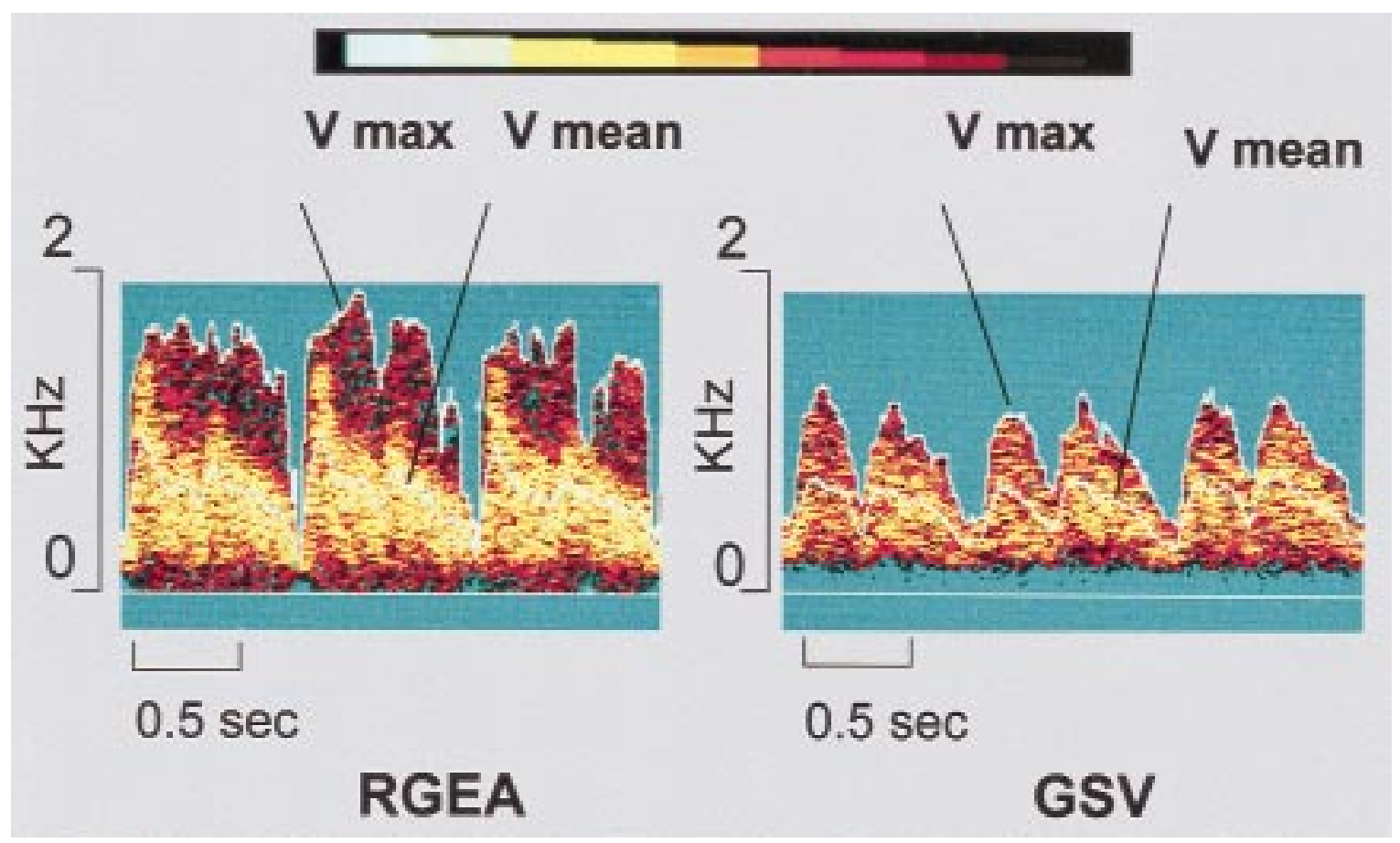

Fig 1. Digitized spectral velocities from 3 cardiac cycles acquired from an RGEA and a GSV graft. The maximum (Vmax) and averaged (Vmean) velocity traces are indicated. A scale of spectral frequency distribution (upper part) indicates the highest (white), the lowest (dark red), and intermediate categories.

ing sites were in the proximal vein graft segment. For the RGEA, the surrounding fat was incised and the measurements were made at a level 2 to $3 \mathrm{~cm}$ distal to the origin of the gastroduodenal artery. The measurements were obtained by placing an acrylic cuff around the vessel and the 2 halves were clipped around it. The ultrasound pencil probe was slotted into the clip and acoustically coupled to the vessel by a small amount of sterile gel. A detailed description of this method was published previously. ${ }^{16}$ The technique was validated by comparing measurements with flow measurements obtained in internal thoracic arteries by an electromagnetic flowmeter $(r=0.97)$ and with in vitro timed-volume collection performed in saphenous veins $(r=0.97) .{ }^{16}$ The parameters measured by the pulsed Doppler flowmeter were flow (milliliters per minute), velocity (centimeters per second), and internal diameter (millimeters) of the vessel. Total resistance of the graft and coronary bed was calculated from mean radial artery pressure divided by mean flow and is expressed in peripheral resistance units. A pulsatility index (PI) was calculated to describe the shape of the curves. It is a dimensionless variable, independent of probe-to-vessel angle. This variable was defined as follows: $\mathrm{PI}=($ Fmax - Fmin $) /$ Fmean, where Fmax is the maximum frequency, Fmin is the minimum frequency, and Fmean is the mean frequency. The pulsed Doppler flowmeter was connected to a real-time spectrum analyzer (Dopstation, Scimed), and the Doppler audio signals were processed by the spectrum analyzer by means of on-line fast Fourier transformation. By performing a highresolution 256 points fast Fourier transformation analysis of the audio Doppler signals, we were able to display the directional spectral information including the maximum and mean frequency traces in real time (Fig 1). The maximum frequency trace was analyzed off-line, and average velocity and peak velocity values were computed. The mean frequency trace was studied in the same manner, and average and peak velocity data were calculated. The pulsed Doppler probe was left in contact with the vessel during the end of the procedure. Flow velocity parameters were continuously acquired, and on-line determination of peak maximum (PkMx) velocity and time-averaged maximal velocity (TAMV) were obtained. The latter parameter was determined by computing the integral of the area under the maximal velocity curve.

Thus graft flow and derived parameters were measured at the following times: just after weaning from $\mathrm{CPB}$ and at the end of the procedure before sternal closure. The latter thorough hemodynamic assessment included the determination of graft flow, maximum trace average velocity, systolic and diastolic peak velocity, mean trace average velocity, corresponding systolic and diastolic peak velocity, internal diameter, resistance, pulsatility index, systemic pressure, and heart rate. In addition, PkMx and TAMV data were acquired every 12 seconds during the period devoted principally to hemostasis and sternal closure.

Data analysis. Perioperative data, including graft hemo- 


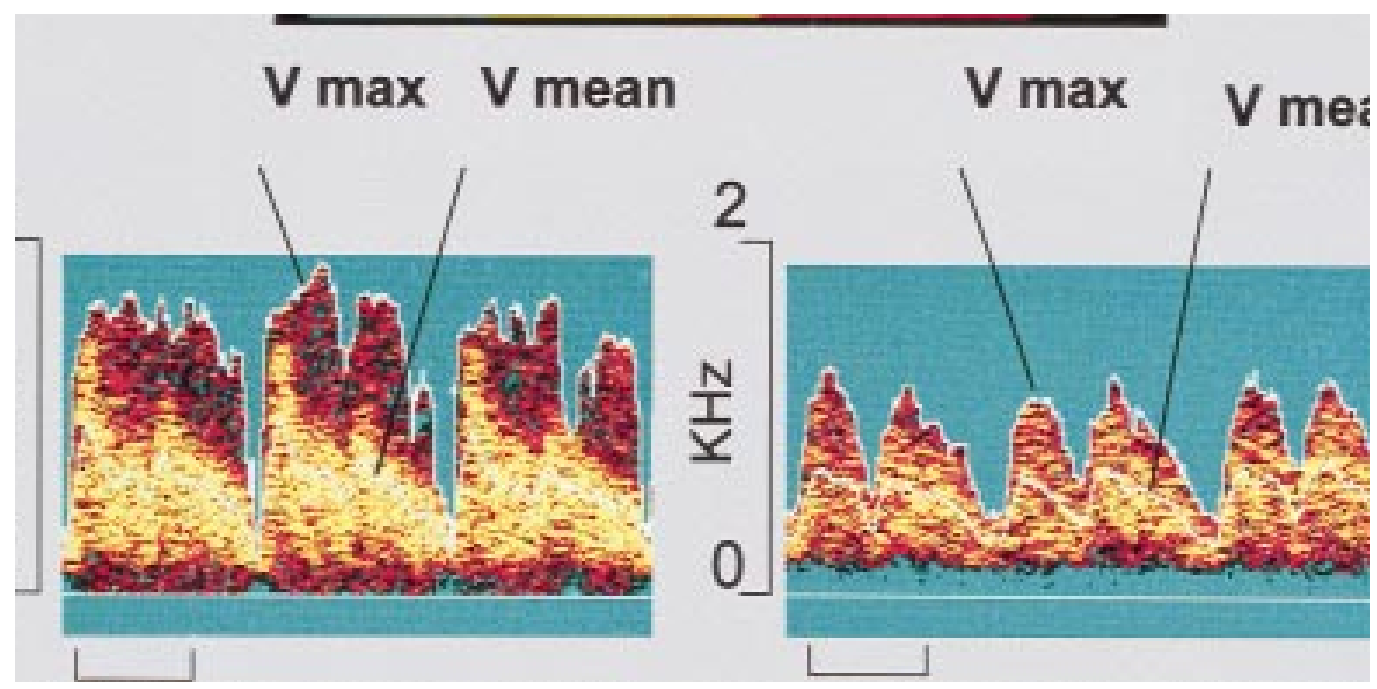

Fig 2. An initial low-flow situation characterized by a predominantly systolic velocity profile. A progressive increase of the systolic and principally diastolic spectral components is observed ending with complete normalization. $S$, Systole; $D$, diastole.

Table III. Hemodynamic assessment

\begin{tabular}{|c|c|c|c|c|c|c|}
\hline & \multicolumn{3}{|c|}{ End $C P B$} & \multicolumn{3}{|c|}{ Chest closure } \\
\hline & $R G E A$ & $G S V$ & P value & $R G E A$ & $G S V$ & $\mathrm{P}$ value \\
\hline Flow (mL/min) & $59.0 \pm 6.7$ & $46.1 \pm 2.7$ & .08 & $57.1 \pm 4.7$ & $46.5 \pm 4.0$ & .10 \\
\hline \multicolumn{7}{|l|}{ Velocity $(\mathrm{cm} / \mathrm{sec})$} \\
\hline \multicolumn{7}{|l|}{ Maximum trace } \\
\hline Average & $20.6 \pm 1.2$ & $17.2 \pm 1.2$ & .05 & $22.4 \pm 1.2$ & $17.2 \pm 1.2$ & .04 \\
\hline Systolic peak & $29.4 \pm 1.2$ & $23.1 \pm 1.3$ & $<.001$ & $30.0 \pm 1.2$ & $22.3 \pm 1.2$ & $<.001$ \\
\hline Diastolic peak & $25.2 \pm 1.4$ & $21.1 \pm 1.2$ & .03 & $27.0 \pm 1.4$ & $20.0 \pm 1.3$ & $<.001$ \\
\hline Systolic/diastolic peak & $1.36 \pm 0.1$ & $1.17 \pm 0.1$ & .13 & $1.22 \pm 0.1$ & $1.23 \pm 0.08$ & .88 \\
\hline \multicolumn{7}{|l|}{ Mean trace } \\
\hline Average & $11.9 \pm 0.7$ & $11.6 \pm 0.8$ & .80 & $12.9 \pm 0.7$ & $11.6 \pm 0.8$ & .22 \\
\hline Systolic peak & $17.7 \pm 0.8$ & $15.9 \pm 1.0$ & .14 & $18.2 \pm 0.8$ & $15.6 \pm 1.0$ & .04 \\
\hline Diastolic peak & $15.2 \pm 0.8$ & $14.6 \pm 1.1$ & .63 & $16.7 \pm 0.9$ & $14.7 \pm 1.1$ & .17 \\
\hline Systolic/diastolic peak & $1.29 \pm 0.07$ & $1.17 \pm 0.05$ & .21 & $1.16 \pm 0.04$ & $1.14 \pm 0.05$ & .75 \\
\hline Resistance (PRU) & $2.4 \pm 0.3$ & $1.9 \pm 0.1$ & .21 & $2.3 \pm 0.4$ & $2.2 \pm 0.2$ & .94 \\
\hline Pulsatility index & $3.5 \pm 0.8$ & $2.6 \pm 0.7$ & .44 & $2.7 \pm 0.3$ & $2.2 \pm 0.2$ & .21 \\
\hline Internal diameter (mm) & $2.4 \pm 0.0$ & $2.2 \pm 0.0^{*}$ & .01 & $2.4 \pm 0.0$ & $2.4 \pm 0.1^{*}$ & .60 \\
\hline $\mathrm{MSP}(\mathrm{mm} \mathrm{Hg})$ & $75 \pm 1$ & $77 \pm 2$ & .39 & $81 \pm 2$ & $80 \pm 2$ & .68 \\
\hline Heart rate (beats/min) & $75 \pm 2$ & $75 \pm 2^{\dagger}$ & .75 & $76 \pm 2$ & $79 \pm 2^{\dagger}$ & .33 \\
\hline
\end{tabular}

$C P B$, Cardiopulmonary bypass; $R G E A$, right gastroepiploic artery; $G S V$, greater saphenous vein; $P R U$, peripheral resistance units; $M S P$, mean systemic pressure. ${ }^{*} P=.01$.

${ }^{\dagger} P=.04$.

dynamic measurements, were collected and entered, contingent with the operation, into the cardiovascular surgery clinical research database. Values are presented as mean \pm standard error of the mean. Clinical data were compared by 2-sample $t$ test (paired or unpaired), Wilcoxon rank sum test, $\chi^{2}$ test, or Fisher exact test, when appropriate. Data obtained repeatedly, such as TAMV and PkMx, were compared by regression analysis of repeated measures using generalized estimating equations, as described by Liang and Zeger. ${ }^{17}$ This analysis allows taking into account simultaneously the influence of the initial value, time, and betweensubject categoric variables. Multiple linear regression analysis of graft flow measured before chest closure was realized with forward selection of variables using the Wald test at 0.05 entry and 0.10 exclusion level. Statistical analyses were performed with the use of the SPSS (SPSS Inc, 

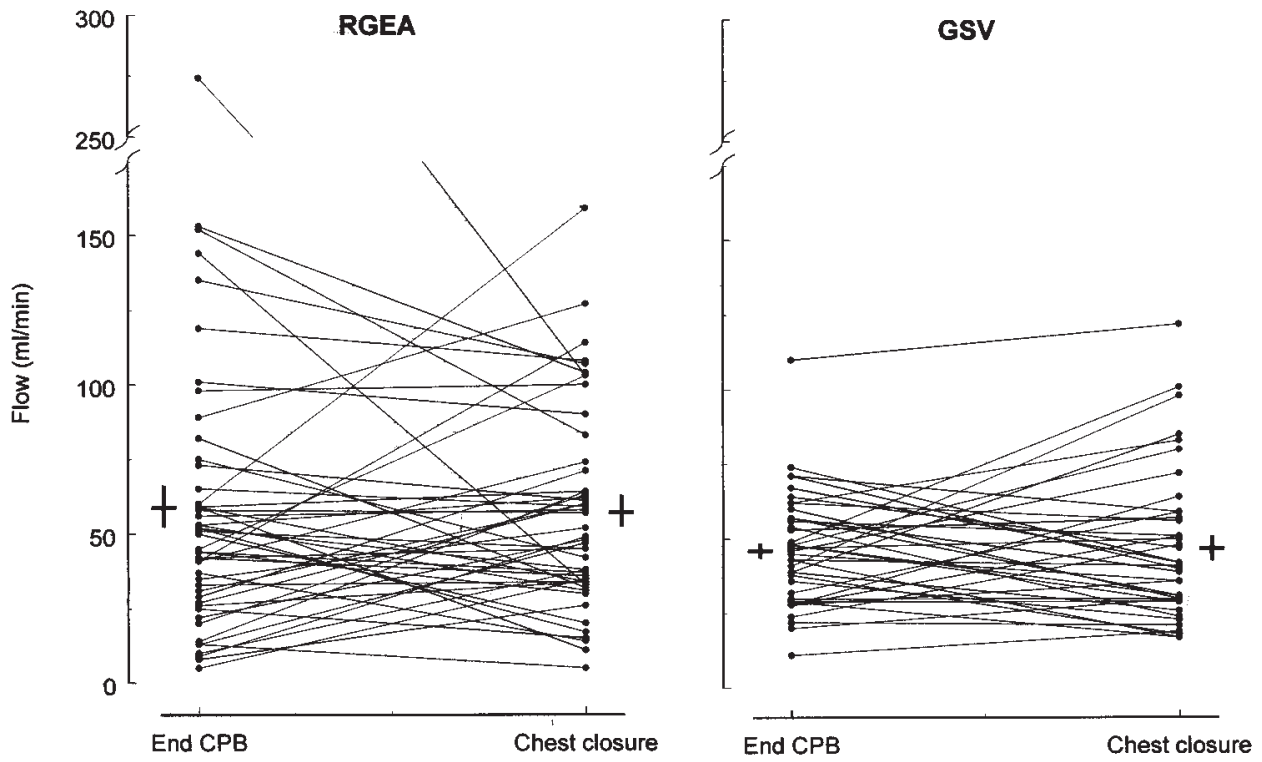

Fig 3. Differences are shown in flow volume of RGEA and GSV grafts immediately after cessation of CPB and before chest closure. Mean values and SEM are indicated. There was no significant difference by paired $t$ test.

Chicago, Ill) software package, except regression analysis of repeated measures, for which the RMGEE program was used. $^{18}$

\section{Results}

Hemodynamic assessment. Flows were measured in all grafts, and none of the patients had complications related to Doppler instrumentation. A comparison of the data obtained during the 2 study periods in RGEA and GSV grafts is depicted in Table III. Systemic pressure and heart rate were similar in the 2 groups. Flow tended to be higher in RGEA grafts, but the difference did not reach a level of statistical significance given the variability of the data. Maximum trace velocities demonstrated higher peak velocities at both study periods and a superior average velocity before chest closure in RGEA grafts. Regarding mean trace velocities, systolic peak velocity measured before chest closure was greater in RGEA grafts. The resistance offered by the graft and the runoff bed expressed by resistance and pulsatility index did not differ between the groups. Surprisingly, internal diameter was significantly smaller in GSV grafts at the end of CPB. Nevertheless, by the end of the procedure it was comparable with the diameter of RGEA grafts.

In 6 cases, a flow rate lower than $10 \mathrm{~mL} / \mathrm{min}$ was observed in the RGEA at the first hemodynamic assessment. In 3 of the cases, an anastomotic twist was evident and flow was restored by adequate graft repositioning. In the 3 other cases, close examination of the distal anastomosis did not reveal any abnormality. Fortunately, velocity increased gradually, as demonstrated during continuous velocity monitoring, and flow reached normal values by the end of the procedure. An example of changes in velocity profile over a prolonged period of monitoring is shown in Fig 2. Furthermore, in 1 patient an initial flow of only 13 $\mathrm{mL} / \mathrm{min}$ was observed in an RGEA graft implanted onto a posterior descending artery that disclosed a $71 \%$ to $90 \%$ proximal stenosis at angiography. There was no history of myocardial infarction, and the preoperative ventriculogram showed no abnormalities (60\% ejection fraction). TAMV remained in the range of 3 to $6 \mathrm{~cm} / \mathrm{s}$ and flow dropped to $10 \mathrm{~mL} / \mathrm{min}$ before chest closure. This was the only situation in which a graft failure was suspected. There were no signs of myocardial ischemia, and the patient made an uneventful recovery.

Comparison of the pairs of measurements made at the 2 time periods (Table III) did not show any difference except for a slight increase of mean systemic pressure and heart rate in the GSV group. Flow modifications are shown in Fig 3. Flow outcome in the RGEA group varied widely, resulting in the absence of significant modification.

Relevant variables likely to influence flow were assessed by multiple linear regression analysis (Appendix 1). Not surprisingly, graft internal diameter was markedly associated with an increase of flow. In addition, RGEA grafts and increased degree of stenosis of the recipient artery correlated positively with the 
Post CPB

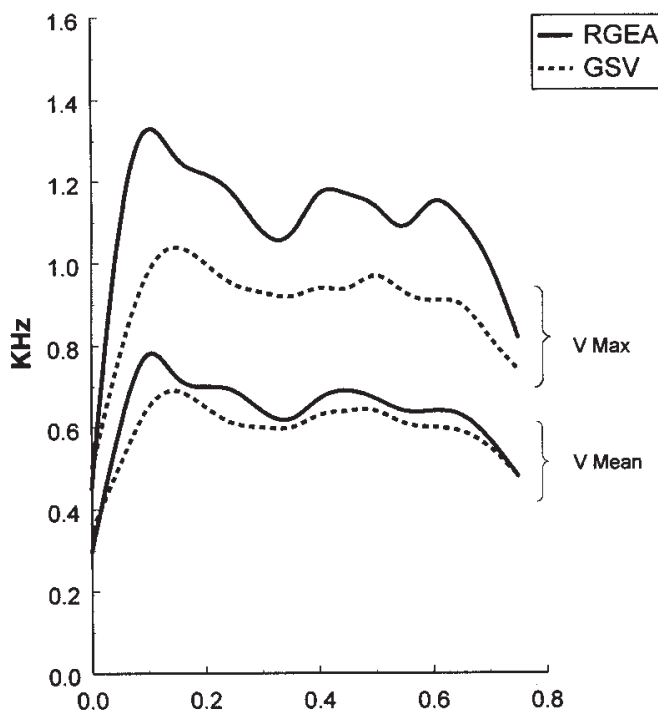

Chest closure

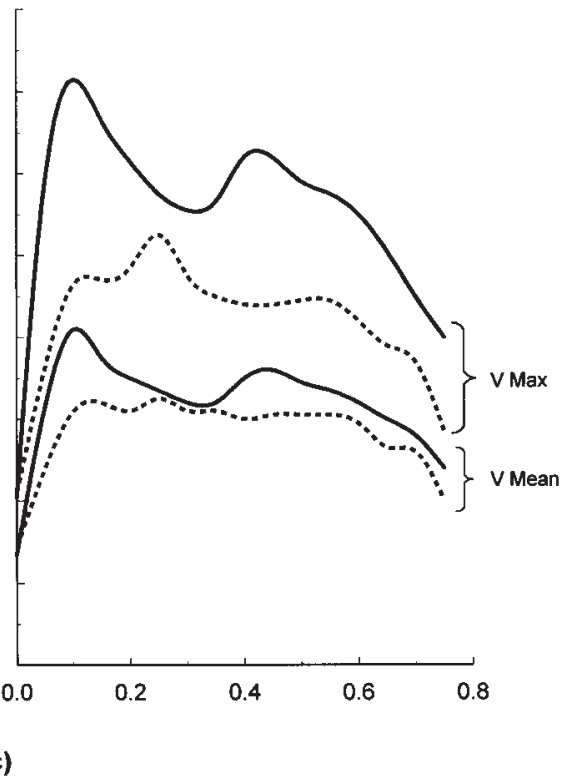

Fig 4. Average waveforms resulting from the pooling of frequency shift data of 1 cardiac cycle. Curves of maximum (VMax) and mean (V Mean) trace velocity, acquired in RGEA and GSV grafts, are compared. The maximum trace frequencies were significantly higher in RGEA grafts at the 2 study periods (post-CPB, $P=.043$; chest closure, $P=.001)$.

magnitude of flow. Age, which was a parameter differing substantially between the 2 groups by univariate analysis, did not influence flow $(P=.84)$.

Waveform shape analysis. The influence of the nature of the graft on the waveform shape was assessed. Given the wide variability of individual Doppler frequency shifts, the maximum and mean frequency trace data of 1 cardiac cycle in each patient were pooled in 4 groups according to the type of graft and the timing of the measurement. The average waveforms resulting from these computations are represented in Fig 4. By comparison of the areas under the curves, the maximum trace frequencies were significantly higher in RGEA grafts during the 2 study periods (post-CPB, $P$ $=.043$; chest closure, $P=.001$ ). By contrast, mean frequencies were similar (post-CPB, $P=.71$; chest closure, $P=.12$ ). Paired comparisons of the velocity traces between the 2 time periods did not show significant differences (maximum trace RGEA, $P=.29$; maximum trace GSV, $P=.44$; average trace RGEA, $P=.38$; average trace GSV, $P=.47$ ).

Velocity trending. Velocities were continuously monitored during a time frame averaging $49 \pm 3$ minutes for GSV grafts and $57 \pm 3$ minutes for RGEA grafts $(P=.041)$. The 8-minute difference is explained by the additional time necessary to complete hemostasis of the RGEA and the greater gastric curvature. The velocity trending is represented in Fig 5. Repeated-measures analysis, using generalized estimating equations, was applied to PkMx and TAMV acquired at 4-minute intervals and limited to a maximal duration of 60 minutes. The following covariants were included in the analysis: type of graft (RGEA or GSV), runoff bed (right coronary artery, posterior descending artery, or posterolateral branch), initial value of the velocity parameter, and time. The PkMx trending was influenced positively by RGEA graft $(P=.003)$, initial PkMx value $(P<.0001)$, and time $(P=.020)$. The trend was toward a constant reduction for GSV grafts $(\mathrm{PkMx}=[1.016(\mathrm{SE} 0.022) \times$ initial PkMx value] $-[0.024($ SE 0.012$) \times$ Time in minutes]). In the same manner, RGEA graft $(P=.001)$, initial value of TAMV $(P<.0001)$, and time $(P=.007)$ positively influenced TAMV trending. The model computed from the generalized estimating equation showed a positive trend of TAMV for RGEA grafts (TAMV = [0.951 $($ SE 0.019) $\times$ initial TAMV value $]+[0.028(\mathrm{SE}$ $0.009) \times$ Time in minutes]).

In-hospital complications. Two patients died after the operation, the first from thrombosis of a mechanical mitral prosthesis and the second from ischemic colitis. None of these patients had RGEA grafts. The only complication specific to the RGEA harvest in the series was bleeding originating from an artery of the greater gastric curvature necessitating reexploration. 


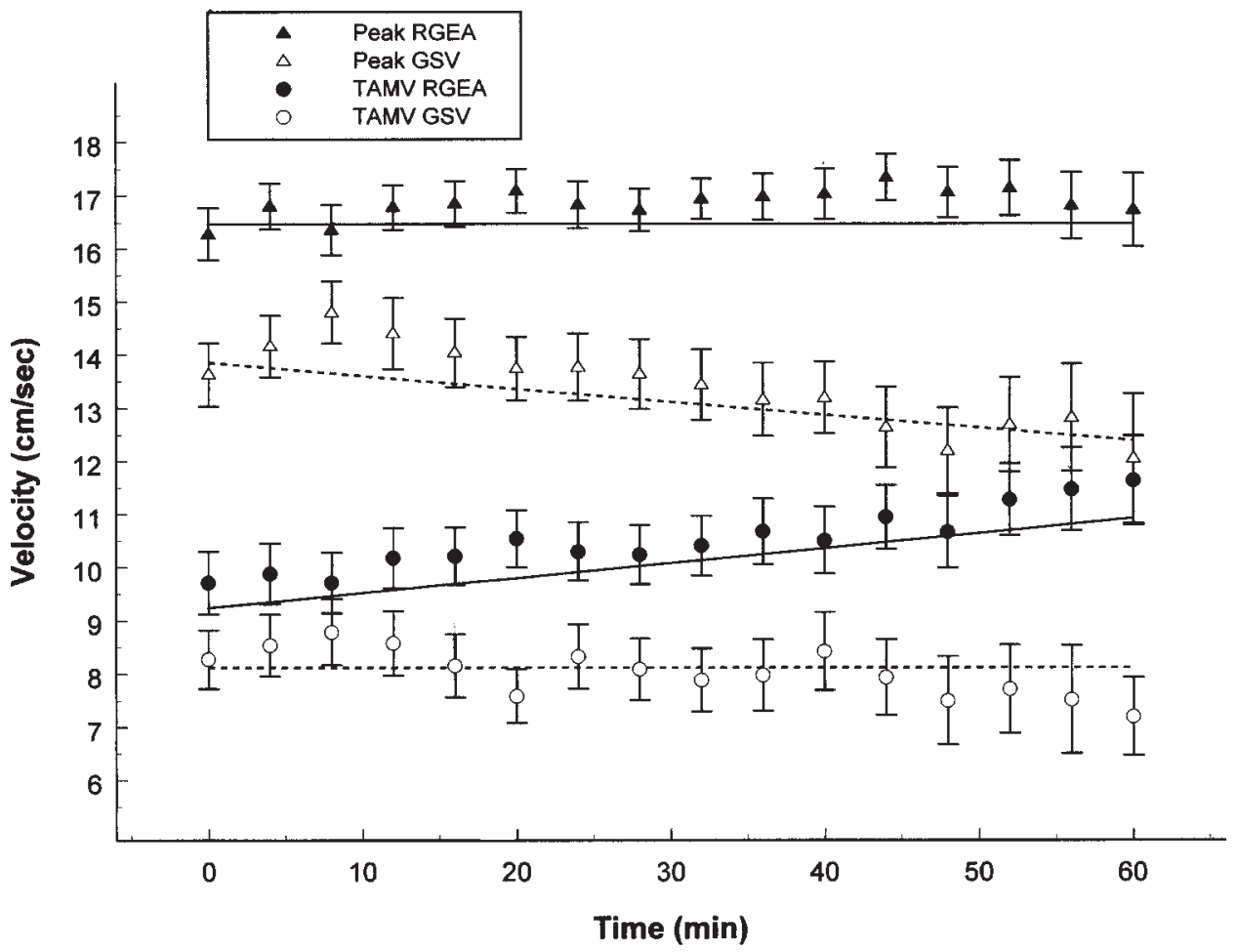

Fig 5. Results are shown of the continuous velocity monitoring realized from the end of CPB until chest closure. The trending of peak maximum velocity $(P k M x)$ and time-averaged maximal velocity (TAMV) acquired from RGEA and GSV bypass grafts is represented. Only 4-minute interval values were plotted. The straight lines are derived from the regression models obtained with the generalized estimating equation. See text for further information.

\section{Discussion}

Comparison of flow volume and derived data. The physiologic capability of the RGEA as a bypass conduit was first assessed by measuring free flow rates and measuring internal diameters at the anastomotic sites. ${ }^{19}$ That report by Mills and associates ${ }^{19}$ pointed out the variability of the diameter of the distal RGEA (which ranged from 1.5 to $4.0 \mathrm{~mm}$ ) and of the free flow of the divided conduit (which ranged from 42 to 660 $\mathrm{mL} / \mathrm{min}$ ). However, the practical value of these data was limited by the fact that in all instances the anastomotic site of the RGEA was from 2 to $8 \mathrm{~cm}$ proximal to the distal end. The arteries at the point of anastomosis were therefore larger than at the distal arteriotomy site at which free flow was measured. Furthermore, no correlation could be demonstrated between the RGEA flow after anastomosis to the target coronary artery, the RGEA flow volume as measured by Doppler echocardiography before takedown, and the RGEA diameter before takedown. ${ }^{12}$

The comparison of flow potential of the RGEA with other available bypass conduits was rarely made. Only Takayama and associates ${ }^{15}$ compared both internal tho- racic artery and RGEA grafts implanted in 16 patients. Velocity was determined with a 5-MHz Doppler miniprobe and the internal diameter of the graft was measured intraoperatively with a probe or calculated from the preoperative angiography data, allowing an estimation of the flow volume. They demonstrated that graft flow recovered just before sternal closure to values almost equal to those measured before takedown. Average flow data were not mentioned in their comparison.

Two studies have involved the determination of RGEA flow volume. Recently, Tavilla, Jacobowitz, and Berreklouw, ${ }^{12}$ using Doppler echocardiography, published the results of flow measurements realized intraoperatively in the RGEA. They obtained a mean flow of $61 \mathrm{~mL} / \mathrm{min}$ and an internal diameter of $2.9 \mathrm{~mm}$, which compares with flow results averaging $59 \mathrm{~mL} / \mathrm{min}$ in the present investigation. In the second study, Agrifoglio and colleague ${ }^{20}$ measured a flow averaging $31 \mathrm{~mL} / \mathrm{min}$ and an internal diameter of $2.1 \mathrm{~mm}$ by a method of transcutaneous Doppler echocardiography realized after the operation. Finally, the internal diameter of the proximal part of the native RGEA was measured by quantitative angiography ${ }^{21}$ : the internal diameter was $2.0 \mathrm{~mm}$ 
at baseline and increased to $2.3 \mathrm{~mm}$ at maximal vasodilation obtained during acetylcholine infusion and to 2.7 $\mathrm{mm}$ after isosorbide dinitrate injection. These data fall in the range of our intraoperative findings, which average $2.4 \mathrm{~mm}$.

Average flow was similar in RGEA and GSV grafts by univariate analysis. Furthermore, multivariate analysis demonstrated a higher flow in RGEA grafts than in GSV grafts. Thus the null hypothesis that arterial grafts, particularly those originating in the descending aorta, have a lower ability to supply blood to the diastolic-dominant coronary circulation ${ }^{14}$ can be rejected. Flow data and derived parameters did not change between the 2 study periods, which corroborates previous studies showing the stability of these flow measurements. ${ }^{15,22}$ The internal diameter measured in GSV grafts immediately after CPB was smaller than in RGEA grafts, and it increased by the end of the procedure. These data demonstrate that GSV grafts obtained at the ankle level are somewhat spastic immediately after reperfusion, which can be explained simply by the fact that the conditions of preservation of the venous grafts (bathing in an electrolyte solution [PlasmaLyte] at room temperature) were not as optimal as for RGEA grafts (perfused with blood and injected with warm undiluted papaverine). Furthermore, although GSV conduits look markedly larger than RGEA grafts, their inner diameter was never found to be greater. Indeed, the internal diameter of the RGEA near the origin from the gastroduodenal artery averages $3.5 \mathrm{~mm}$ according to Saito and associates ${ }^{23}$ and $4.0 \mathrm{~mm}$ according to Mills and Everson. ${ }^{8}$ By contrast, GSV grafts have an inner diameter averaging $3.2 \mathrm{~mm}$ and ranging from 1.9 to 4.1 $\mathrm{mm} .^{24}$ This can be explained by a medial thickness reaching $517 \mu \mathrm{m}$ in the upper leg GSV and $361 \mu \mathrm{m}$ in the lower leg GSV, ${ }^{25}$ whereas the medial thickness of the RGEA is only $291 \mu \mathrm{m}$.

Comparison of waveform shape. The waveform shape was markedly influenced by the nature of the conduits. Indeed, the RGEA was characterized by a higher maximum trace velocity (average, systolic, and diastolic peak), but the average mean trace velocity did not differ from that of the GSV. This is corroborated by the curve morphology analysis (Fig 4), where only maximum velocity was significantly superior in RGEAs. The characteristic waveform shape of the RGEA can be explained by the wall structure of the graft (elasticity, compliance), the length (RGEA being longer and originating from another splanchnic artery), and by the increased time delay between ventricular systole and the arrival of the pulse wave into the artery. ${ }^{14}$ The latter factors determine a higher dispersion of velocity spectra and explain the wide range of velocities observed in RGEAs. These observations may have practical applications because flow analyses based on the estimation of maximal velocity contours, such as the area under the maximum velocity curve, would overestimate RGEA flows; therefore one should consider average velocity for estimation of flow.

Velocity trending. The vasospasticity of the RGEA was demonstrated by numerous studies realized in vitro despite conflicting data resulting from the diversity of the methods used. The vasoactive properties of internal thoracic arteries and RGEAs were compared by using vascular rings studied in organ bath experiments. Generally, RGEA segments had stronger contractions to depolarizing agents (potassium chloride) and adrenoreceptor agonists (norepinephrine, phenylephrine) than internal thoracic artery segments. ${ }^{3-6}$ In vivo studies are rare, although spasm of the RGEA is frequently triggered by mechanical stimulation, such as catheter stimulation at angiography or surgical manipulation. Hanet and colleagues ${ }^{7}$ demonstrated greater changes in luminal diameter in response to methylergometrine-induced vasoconstriction than in the grafted coronary arteries. The other reports deal with occasional cases of transient vasospasm at postoperative cardiac catheterization. $^{8-11}$

The present study was designed to detect the consequences of a severe spasm of the distal RGEA leading to increase in graft resistance, reduction of velocity, and flow at the level of the proximal RGEA where measurements are made. We observed in 3 cases an initial low flow that improved spontaneously. These examples can be explained not only by spasm at the level of the anastomosis but also by temporarily elevated resistance in the runoff bed related to ischemic heart arrest. Because there was no direct determination of velocity or visualization of spasm in the conduit at the distal end, we cannot differentiate between these 2 phenomena; however, the RGEA was specifically associated with a positive trend of PkMx and TAMV. This significant increase in velocity may be explained by a reduction in graft resistance due to the alleviation of spasm at the distal end. In 3 further cases, the reduction in flow was clearly related to twisting or kinking and was improved simply by modifying the position of the graft.

\section{Conclusions}

The hypothesis that RGEA grafts have a lower ability to supply blood to the diastolic-dominant coronary circulation can be rejected because flow in RGEA grafts was not inferior to that in GSV grafts. The second hypothesis, that waveform shapes differ, was verified. The RGEA grafts have markedly higher maximal 
velocity curves. We can thus consider that flow is regulated primarily by the runoff bed, whereas the waveform shape is defined by the nature of the graft. Spasm was suspected in a limited number of cases but was much less frequent than suggested by pharmacologic experimentation.

\section{REFERENCES}

1. Suma H, Amano A, Horii T, Kigawa I, Fukuda S, Wanibuchi Y. Gastroepiploic artery graft in 400 patients. Eur J Cardiothorac Surg 1996;10:6-10

2. Voutilainen S, Verkkala K, Jarvinen A, Keto P. Angiographic 5year follow-up study of right gastroepiploic artery grafts. Ann Thorac Surg 1996;62:501-5.

3. Chardigny C, Jebara VA, Acar C, et al. Vasoreactivity of the radial artery: comparison with the internal mammary and gastroepiploic arteries with implications for coronary artery surgery. Circulation 1993;88(Suppl):II115-27.

4. Dignan RJ, Yeh TJ, Dyke CM, et al. Reactivity of gastroepiploic and internal mammary arteries: relevance to coronary artery bypass grafting. J Thorac Cardiovasc Surg 1992;103:116-22.

5. He GW, Yang CQ. Comparison among arterial grafts and coronary artery: an attempt at functional classification. $\mathrm{J}$ Thorac Cardiovasc Surg 1995;109:707-15.

6. Yang Z, Siebenmann R, Studer M, Egloff L, Luscher TF. Similar endothelium-dependent relaxation, but enhanced contractility, of the right gastroepiploic artery as compared with the internal mammary artery. J Thorac Cardiovasc Surg 1992;104:459-64

7. Hanet C, Semaan C, Khoury G, Dion R, Robert A. Differences in vasoreactivity between gastroepiploic artery grafts late after bypass surgery and grafted coronary arteries. Circulation 1994;90 (Suppl):II155-9.

8. Mills NL, Everson CT. Right gastroepiploic artery: a third arterial conduit for coronary bypass. Ann Thorac Surg 1989;47:706-11.

9. Suma H. Spasm of the gastroepiploic artery graft. Ann Thorac Surg 1990;49:166-70.

10. Isshiki T, Yamaguchi T, Nakamura M, et al. Postoperative angiographic evaluation of gastroepiploic artery grafts: technical considerations and short-term patency. Cathet Cardiovasc Diagn 1990;21:233-8.

11. Cate CM, Gitter R, Jett K. Spasm of the gastroepiploic artery used for coronary artery bypass grafting. Am J Cardiol 1996;77:1022-3.

12. Tavilla G, Jacobowitz JJ, Berreklouw E. Intraoperative blood flow measurement of the right gastroepiploic artery using pulsed Doppler echocardiography. Ann Thorac Surg 1997;64:426-31.

13. Grandjean JG, Boonstra PW, den Heyer P, Ebels T. Arterial revascularization with the right gastroepiploic artery and internal mammary arteries in 300 patients. J Thorac Cardiovasc Surg 1994;107:1309-15.

14. Tedoriya T, Kawasuji M, Ueyama K, Sakakibara N, Takemura H, Watanabe Y. Physiologic characteristics of coronary artery bypass grafts. Ann Thorac Surg 1993;56:951-6.

15. Takayama T, Suma H, Wanibuchi Y, et al. Doppler miniprobe to measure arterial graft flow in coronary artery bypass grafting. Ann Thorac Surg 1991;52:322-4.

16. Louagie YAG, Haxhe JP, Jamart J, Buche M, Schoevaerdts JC. Intraoperative assessment of coronary artery bypass grafts using a pulsed Doppler flowmeter. Ann Thorac Surg 1994;58:742-9.
17. Liang KY, Zeger SL. Longitudinal data analysis using generalized linear models. Biometrika 1986;73:13-22.

18. Davis CS. A computer program for regression analysis of repeated measures using generalized estimating equations. Comput Methods Programs Biomed 1993;40:15-31.

19. Mills NL, Hockmuth DR, Everson CT, Robart CC. Right gastroepiploic artery used for coronary artery bypass grafting: evaluation of flow characteristics and size. J Thorac Cardiovasc Surg 1993;106:579-85.

20. Agrifoglio M, Di MS, Antona C, Zanobini M, Alamanni F, Biglioli P. Pedicled arterial grafts in coronary surgery: postoperative echo color-Doppler study. J Cardiovasc Surg Torino 1996;37:53-7.

21. Gurné O, Chenu P, Timmermans P, Marchandise B, Schroeder E. Evaluation in vivo of the endothelial function of the native gastroepiploic artery. Am Heart J 1998;135:146-51.

22. Louagie YAG, Haxhe JP, Buche M, Schoevaerdts JC. Intraoperative electromagnetic flowmeter measurements in coronary artery bypass grafts. Ann Thorac Surg 1994;57:357-64.

23. Saito T, Suma H, Terada Y, Wanibuchi Y, Fukuda S, Furuta S. Availability of the in situ right gastroepiploic artery for coronary artery bypass. Ann Thorac Surg 1992;53:266-8.

24. Chen AH, Nakao T, Brodman RF, Greenberg M, Charney R, Menegus M, et al. Early postoperative angiographic assessment of radial artery grafts used for coronary artery bypass grafting. J Thorac Cardiovasc Surg 1996;111:1208-12.

23. Louagie YA, Legrand-Monsieur A, Lavenne-Pardonge E, et al. Viability of long-term cryopreserved human saphenous veins. J Cardiovasc Surg (Torino) 1990;31:92-100.

\section{Appendix 1}

Independent variables

Age: years

Sex: male/female

Body surface area: $\mathrm{m}^{2}$

Diabetes: yes/no

Ejection fraction: percent

Posterobasal contractility: normokinesia, hypokinesia, akinesia, or dyskinesia

Recipient artery stenosis: $51 \%-70 \%, 71 \%-90 \%, 91 \%$ $99 \%$, or $100 \%$

Dominance: right, left, or balanced

Bypassed territory: right coronary artery, posterior descending artery, or posterolateral branch

Quality of runoff bed: normal, anastomotic plaque, diffusely atheromatous, heavily calcified, need for endarterectomy

Graft: RGEA or GSV

Graft internal diameter: $\mathrm{mm}$

Mean systemic pressure: $\mathrm{mm} \mathrm{Hg}$

\section{Dependent variable}

Flow in bypass graft (before chest closure): $\mathrm{mL} / \mathrm{min}$

Variables selected in the model

Graft internal diameter: $\beta$ coefficient \pm SE $(\beta) 33.27 \pm$ 5.27; $P<.001$

Graft: $\beta$ coefficient \pm SE $(\beta) 11.17 \pm 5.31 ; P=.038$

Recipient artery stenosis: $\beta$ coefficient \pm SE $(\beta) 4.29 \pm$ 2.39; $P=.076$ 